\title{
Error Analysis and Second Language Writing
}

\author{
Ali Akbar Khansir \\ Bushehr University of Medical Sciences and Health Services, Iran
}

\begin{abstract}
The purpose of the study is to compare and examine types of written errors by EFL and ESL learners at under graduate level in English Language and suggest remedial measures to overcome the committing of errors. The data for the study were 200 students in the age range of 20 to24 at under graduate level in Mysore, India as ESL learners and Bushehr, Iran as EFL learners participated in this study. The results of the study indicate that the total number of errors committed by the Iranian students was 3045 and that of their Indian peers' was 3274. The maximum errors made by the subjects were from the realm of 'punctuation' (1387). The number of errors made by the Indian students in the use of punctuation was 718 which came to $22 \%$ for errors in punctuation. The Iranian students committed 669 errors. They constituted $22 \%$ of errors for punctuation. Thus, the minimum number of errors recorded in writing in this study was 'spelling.' The total number of errors in the use of spelling was 1050 . The number of errors committed by the Iranian students in the use of spelling was 578 which come to $19 \%$ for errors in spelling. The number of errors committed by the Indian students was 472 . They constituted $14 \%$ of errors for spelling.
\end{abstract}

\section{Index Terms - errors, ESL learners, EFL learners, written errors}

\section{INTRODUCTION}

The aim of the study is to examine the written errors such as paragraph, punctuation, articles, spelling, and conjunction in writing of Iranian and Indian students. With the increasing number of foreign language classrooms today, the role of error analysis can be regarded as a 'device' the learner uses in order to learn. Researches have provided empirical evidences pointing to emphasis on learners' errors as an effective means of improving language of students. Corder (1974, P.125) viewed "the study of error is part of the investigation of the process of language learning. In this respect, it resembles methodologically the study of the acquisition of the mother tongues. It provides us with a picture of linguistic development of a learner and may give us indications as to the learning process". It is generally felt that the second and foreign language learners face a lot of problems in English language in general and in particular in writing the English language. That is one of the reasons why the researcher has researched this field. Students commit repeated errors in using the target language. There is a great need for such a study to point out why errors are committed by the students and then we need to bring out few remedial measures to enable the students to improve their language and use English flawlessly.

It is felt that Iranian and Indian students have not properly developed the skill in writing. So far it has been observed by the researcher on his visits to the universities and his discussion with teachers; that the students of English at under graduate level seem to have not acquired competence in writing skills. Corder (1973, P. 262) argued that studying student's errors also has immediate practical applications for foreign language teachers: Errors provide feedback; they tell the teachers something about the effectiveness of his teaching materials and his teaching techniques, and show him what parts of the syllabus he has been following have been inadequately learned or taught and need further attention. They enable him to decide whether he must devote more time to the item he has been working on. This is the day-today value of errors. But in terms of broader planning and with a new group of learners they provide the information for designing a remedial syllabus or a programme of re-teaching. Stig (1975) argued that the aim of an error analysis is an analysis of the learner's errors gives us evidence of his competence in the foreign language. We also gain valuable information concerning learners' difficulties at different stages. Such information is important for the planning of courses and the construction of teaching materials.

The present study attempts to reveal written errors of English learners at under graduate level in Mysore University in India and Bushehr Islamic Azad University in Iran. This study investigates written errors in aforementioned countries. It seems worth mentioning that English is considered as a second and foreign language in India and Iran respectively. However, this study tries to analyze the problems involved in acquiring the writing skill of the students who study English as an optional subject.

\section{REVIEW OF THE PIONEERING STUdIES}

Victor (1973) considered an analysis of errors in composition writing. He collected fifty two books which are used in composition writing over the last four terms, and then he classified all the errors. He believed no two people would have classified the results in quite the same way and several errors could fall into two or more categories. According to him classifications of errors were such as: Spelling, Punctuation, Sentence structure, Verb groups, Noun groups, Pronouns Adjectives, Prepositions, Intensifiers, Confusion or misuse of words and idioms, Contractions, abbreviations 
and informalities, Repetition and circumlocution, and Carelessness. Schachter (1974) considered students' English relative clauses from Persian, Arabic, Chinese and Japanese. He believed that error analysis will reveal to the investigator just what difficulties the learners have in fact: the difficulties in the target language will show up as errors in production or the frequency of occurrence of specific errors will give evidence of their relative difficulty.

Ratna shielamani (1998) analyzed conjunction usage in the written compositions of a group of fifty advanced learners of English in India. The study showed that the students have made quite a number of errors in the use of conjunctions. Although they can be considered learners at an advanced level, they seem to make mistakes in the use of simple connective devices. The specific types of errors include using punctuation instead of conjunction and using both punctuation and conjunction inconsistently. Others involve using the wrong conjunction and omission or intrusion of "that" to different degrees, redundancy reduction ignorance of the relationship between words like antonym and hyponymy, and ignorance of the relationships between clauses like coordination or subordination appear to be important factors. It is evident from this study that the use of conjunctions is also connected to the use of punctuation. A look at most of the composition exercises of Indian learners showed how rich and suitable a field of error analysis punctuation offers. This study can be useful in constructing controlled tests to find out the learners' ability to handle specific functions of those items. Bhatia (1975) chose students for his study from the second year B.A. Class in the pass course stream. Their first language was Hindi. He discussed in detail, the approach to error analysis of students compositions. The composition works of a hundred students were considered and then, the five chosen topics were selected. The areas of investigation were two: a) errors at the level of mechanics, i.e., errors of grammatical nature within the sentence; and b) errors at the level of organization, i.e., errors of paragraph development, which included such points as relevance, order, clarity of construction, and adequate development, of what is called "content comprehensiveness". Therefore, analysis of areas of errors both in mechanics and in organization offer a significant insight into the nature of difficulties in writing faced by second language learners. He concluded that the composition training program suggested in the study is aimed at helping the students achieve intelligible paragraphs in acceptable English through logical development. The suggested classroom activities are meant to help them learn to use both the correct grammatical forms and to develop some competence in their writing. Kharma (1981) considered articles errors of 128 Arab students in department of English in Kuwait. Out of 128 students, 41 of the students were male and 87 females. In this study, three tools employed as follows:

1. A special test which was similar to both of the groups

2. A comparative study of the English and Arabic uses of the articles

3. An examination of a number of the essays written by the students

Thus the test consisted of 40 items .each items, consisted of a slot to be filled in by "a", "an", "the" or "no article." In the study, the author collected about 2950 syntactic errors from essays written by the students at the English Department of Kuwait University over the last few years, but about 300 of the errors belong to the category of errors dealt with in this paper. Out of 300 errors in the use of the definite / indefinite articles in English were classified in terms of their percentages as follows:

1. In the use of "the" $50 \%$

2. In the use of no article $37 \%$

3. In the use of "a/an" $13 \%$

He found that many kinds of errors were due to Arabic interference and other errors were due to wrong strategies or tactics such as false analogy or over generalization or wrong equation of the two systems. He also said that responsible for most errors may due to inadequate teaching.

Radwan (1988) examined the types of grammatical and lexical errors in the nominal group. The result of his study showed that the errors made in the use of articles had the highest percentage. This was followed by relative-clause errors, genitive errors, number errors, word class errors, and then other miscellaneous errors.

Belhaaj (1997) investigated the errors his students generated in the translation papers. The result of the study showed that the grammatical errors generated by the students were arranged according to their frequency as follows: verb formed tense errors, relative clause, adjective errors, preposition errors, noun errors, article errors, and miscellaneous. The importance of this research paper is that it describes a cross-level investigation of errors to examine the acquisition of English grammar across the four levels of the Department of English, Al-Azhar University -Gaza. It also aims at pinpointing some English language segments that ought to be of immediate concern to teachers in the department.

Khansir (2008) analyzed syntactical errors of a group of one hundred college students enrolled in Second Year B.Com at Mysore University in India. The aim of the study was to classify "errors" made by the students at the sentence levels such as: Auxiliary verbs, passive and tenses. The research showed errors committed in the use of auxiliary verbs, passive forms and tenses. The study indicated that there exist systematic errors in learner's target language. Within the perimeter of the paper, the errors pertaining to auxiliary verbs, passive voice, and tenses indicated that teaching English is not satisfactory in the colleges, and that learning strategies are the cause of errors.

\section{HYPOTHESES OF THE STUDY}

The following hypotheses are formulated:

H 1. There is a significant difference in types of errors in writing between Iranian and Indian students. 
H 2. There is a significant difference in types of errors in paragraph between Iranian and Indian students.

$\mathrm{H}$ 3.There is a significant difference in types of errors in punctuation between Iranian and Indian students.

$\mathrm{H}$ 4. There is a significant difference in types of errors in articles between Iranian and Indian students.

$\mathrm{H}$ 5. There is a significant difference in types of errors in spelling between Iranian and Indian students.

H 6. There is a significant difference in types of errors in conjunction between Iranian and Indian students.

\section{METHODOLOGY}

The present study concentrates on the errors of writing of learners of English at under-graduate level. The methodology adopted in this study consisted of the processes: Research design; Data collection; and Data analysis. By the use of the tests, the errors in writing by Iranian and Indian students at under graduate level will be analyzed, and valuable remedial measures suggested. This study is implemented on the basis of an ex-post facto design. The reasons behind choosing such a design such as no control over the manipulation of the independent variables; no treatment will be given to the subjects; and the present researcher in this study required looking for some degree of relationship between the variables rather than a cause effect relationship. The collection of data in any study is usually determined by its objectives. The collection of data in this study is used in terms of the objective: a) to examine types of errors in target language (i.e. English language); b) to compare types of errors in writing of Iranian and Indian students; to suggest remedial measure to overcome the committing of errors. The data was analyzed utilizing the computer programmed from SPSS in this research.

\section{A. Participants}

The subjects for this study were 200 students in the age range of 20 to 24 at under-graduate level in Mysore, India as second language learners and Bushehr, Iran as foreign language learners. Ages of the subjects are presented in the following table:

TABLE 1.

AGE AND FREQUENCY OF THE SUBJECTS BETWEEN IRAN AND INDIA

\begin{tabular}{|l|l|l|l|l|}
\hline Country & Iran & India & Percent \\
\hline Age & Frequency & Percent & Frequency & 72 \\
\hline 20 & - & - & 72 & 16 \\
\hline 21 & 59 & 59 & 16 & 4 \\
\hline 22 & 18 & 18 & 4 & 4 \\
\hline 23 & 15 & 15 & 4 & 4 \\
\hline 24 & 8 & 8 & 4 & 100 \\
\hline Total & 100 & 100 & 100 & \\
\hline
\end{tabular}

The groups of the subjects were comprised of 124 females and 76 males who were selected for computer analysis from two universities after they took a General English Proficiency test and the Grammatical Judgement Test. 100 out of the 200 selected students of B.A. (English) III year studying in 5 colleges of the Mysore Colleges affiliated to the University of Mysore in Mysore city were participated for the purpose of collecting data. These colleges were used to collect data as follows:

1. J.S.S.College for Women.

2. MaharajaCollege.

3. MahajanaCollege.

4. MaharanisCollege.

5. Evening college.

And also 100 Iranian students of B.A. (English) III year studying in department of English from Bushehr Islamic Azad University in Bushehr city were participated for the data collection. Thus, the number and the educational level of the students selected from both groups were the same. Both Iranian and Indian participants in the current study belong to middle class.

\section{B. Instruments}

The instruments utilized in this study were: General English Proficiency Test, Background Questionnaire, and Grammatical Judgment Test (G.J.T).The General English Proficiency Test (Transparent) consisted of 50 multiple choice vocabulary, grammar, and reading comprehension items. The test was selected to assess the participant's level of proficiency in English. In administering the test, the Researcher piloted the test for the target groups with the same level In addition, 15 students in each target group, in two countries, with the same level and similar characteristics to participants of this research participated in the pilot study. The General English Proficiency Test was found to be appropriate for the participants' performing level. Its reliability through the K-R 21 formula turned out to be .64 for Iranian and .68 to the Indian students. In this experiment, the students who scored between one standard deviation below or above the mean score were selected for the purpose of collecting data in the present study .The background questionnaire for this study was designed to elicit information on subjects. The questionnaire developed by the present researcher consisted of 13 questions which were related to their residential address; age, language use, information 
about the parents, details about siblings, language attitude, etc. Grammatical test has always been used as one method for collecting data. Grammar tests are designed to measure learner's proficiency in an academic work. Grammatical test is a test which aims to measure knowledge or control of grammatical structures, as compared with tests of ability to use the language, such as performance tests. Crystal (1997) mentioned that the function of the grammatical judgment test (G.J.T.) is distinguished between grammatical and ungrammatical sentences and he added that it judges whether these sentences are well-formed or ill-formed. The grammatical judgment test utilized in this study was a combination of the essay writing and multiple-choice which consisted of 5 items such as paragraph, punctuation, articles, spelling, and conjunction. The test was used to identify the type of errors in writing of Iranian, and Indian students. It was chosen to examine the ability of the subjects in selecting the correct items in English. In administering the test, the Researcher carried out a pilot test for the target groups with the same level. In addition, 15 students of each target group in the two countries with the same level of proficiency and educational level and also with similar characteristics to the participants selected for this study have been piloted. To ensure whether the grammatical judgment test is appropriate for subjects of the current study, the Researcher experimented with the KR-21 formula. Applying this formula to measure the reliability of grammatical judgment test for both Iranian and Indian students appeared .61 and .63 respectively.

\section{Procedure}

To achieve the objectives of this study the procedures were adopted: Development of the questionnaire, Administration of the proficiency test, Development of the grammaticality judgment test and its administration, and Analysis of collected data. Before focusing on the grammaticality judgment test which plays the role of a pedestal function in this study, the present investigator developed and administered the background questionnaire and English general proficiency test. The administration of the proficiency test was administered to the Iranian and Indian students respectively. Those students who score between one standard deviation below or above the mean were selected to participate in the next stage of the research. 250 students as total were selected to participate in the next stage, 120 of them were Iranian students studying English in department of English at Bushehr Islamic Azad University in Bushehr city in Iran and others 130 students studying English in colleges of Mysore University in My sore City in India. The background questionnaire was designed in order to elicit information on subjects. The questionnaire consisted of 13 items which were related to their residential address, age, language use, information about the parents, details about siblings, language attitude etc. The test was administered to the Iranian and Indian students respectively. The time limit was, therefore, set. Thus, before the collection of data, the participants were informed that the purpose of the study was to investigate a research work and the test result would not affect their annual examination results or any other results. The grammaticality judgment test was chosen to help in the fulfillment of aims set forth in this study. The test was administered to the Iranian and Indian students respectively. The time-limit was set in such a way as to allow all the students to attempt every item in the test with ease. The researcher cleared the students' doubts during the test. The Researcher had to exclude 50 students from this study, because they had skipped answering most of questions. The remainders were selected for computer analysis. The data was analyzed utilizing a T-test statistical technique in order to answer the research hypothesis posed in this study. The analysis of data was concerned with the tests: General English Proficiency Test, Background Questionnaire, and Grammatical Judgment Test (G.J.T.). The tests were analyzed utilizing the computer programmed from SPSS. The statistical analysis proceeded in three steps: in the first analysis, before making any attempt to investigate the six hypotheses of this study, (Errors of this study), the General English Proficiency Test was examined. The actual scores of the subjects on the test were examined. After this analysis, the subjects were selected for the purpose of the collecting data. In second analysis, the Background Questionnaire was used to elicit information on the subjects. In third analysis, the Grammatical Judgment Test was used to investigate the six hypotheses of the study and the errors committed by the subjects between the two countries. The analysis of work in this study was concerned with the processes: Classification of errors, Comparison of errors, Explanation of errors, and Suggestion of remedial measure. In this process, an attempt was made to classify errors in writing. In the second process, an attempt was made to compare types of errors in writing of Iranian and Indian students. The total numbers of errors by the subjects in writing were compared between the two groups. In the third process, wherever possible an effort is made to explain the errors in terms of whether an error is due to incomplete knowledge or lack of knowledge of English rules, etc. And, in the next process, the last attempt was made to suggest remedial measures to overcome the committing of errors on the basis of insight gained into the nature of errors in second and foreign language learning for second and foreign language learners. The aim is to help the students to improve their language and use English flawlessly.

\section{RESULTS AND DisCUSSION}

The 6319 errors which were utilized in writing for this study were classified into five major categories. Based on the category, it was found that the total number of errors made by the Indian students was 3274 and their Iranian Peers' errors were 3045 . The five major categories came in table 2: 
TABLE 2.

NUMBER AND PERCENTAGE OF WRITTEN ERRORS BETWEEN IRANIAN AND INDIAN STUDENTS

\begin{tabular}{|l|l|l|l|l|l|}
\hline \multirow{2}{*}{$\begin{array}{l}\text { SI } \\
\text { No }\end{array}$} & \multirow{2}{*}{ Test item } & Iran & Percentage & India & Number \\
\cline { 3 - 6 } & & Number & 20 & 638 & 19 \\
\hline 1 & Paragraph & 611 & 19 & 689 & 22 \\
\hline 2 & Conjunction & 569 & 20 & 757 & 23 \\
\hline 3 & Article & 618 & 22 & 718 & 22 \\
\hline 4 & Punctuation & 669 & 19 & 472 & 14 \\
\hline 5 & Spelling & 578 & 100 & 3274 & 100 \\
\hline 6 & Total & 3045 & & & \\
\hline
\end{tabular}

The above table indicates that the maximum errors made by the subjects were from the realm of 'punctuation' (1387). The number of errors made by the Indian students in the use of punctuation was 718 which came to $22 \%$ for errors in punctuation. The Iranian students committed 669 errors. They constituted $22 \%$ of errors for punctuation. Thus, the minimum number of errors recorded in writing in this study was 'spelling.' The total number of errors in the use of spelling was 1050 . The number of errors committed by the Iranian students in the use of spelling was 578 which come to $19 \%$ for errors in spelling. The number of errors committed by the Indian students was 472 . They constituted $14 \%$ of errors for spelling. The other areas, in which the incidence of errors that vary from error type to error type, were: 'Paragraph' (1249). The Iranian students committed 611 errors which came to $20 \%$ and the Indian students' errors were 638 which came to $19 \%$ for errors in paragraph. 'Conjunction' (1258). The number of the Indian students' errors was 689 which came to $22 \%$ and their Iranian peers' errors were 569 that constituted $19 \%$ of errors for conjunction. The number of the Iranian students' errors was 618 which came to $20 \%$ and the number of the Indian students' errors was 757. They constituted $23 \%$ of errors for article. Writing tests encompassed sub-categories that are presented as follows:

In paragraph, the maximum errors observed in the selected connectors among the students in this study. In this subcategory, the number of the Iranian students' errors was 386 which came to $63 \%$ and their Indian peers' errors were 393 that constituted $62 \%$ of errors for paragraph. The minimum number of errors were in selected topic sentence, in this sub-category, the number of the Iranian students' errors were 41 which came to $7 \%$. The Indian students' errors were 41. They constituted $6 \%$ of errors for paragraph.

In conjunction, the major errors observed are wrong use of subordinating conjunctions. In this sub- category, the number of the Indian students' errors was 479 which came to $69.5 \%$ and their Iranian peers' errors were 410 which came to $72 \%$ for errors in conjunction. The students seemed to have a tremendous difficulty with both coordinate and subordinate conjunctions. They did not know the use of conjunction properly. The learners were not exactly sure where it is optional and how to use the conjunction at appropriate place.

In article, the maximum error observed is the wrong use of the indefinite article 'a' for the definite article 'the.' In this sub-category, the number of the Iranian students' errors was 137 , which came to $22 \%$ and their Indian peers' errors were 235 which came to $32 \%$ for errors in article. The minimum number of errors was omission of the indefinite article ' $a$ '. In this sub-category, the Iranian students committed 16 errors which came to $2.6 \%$ and the Indian students' errors were 6 . They constituted $0.08 \%$ of errors. The subjects seemed to have not mastered in the use of the English definite and indefinite articles in English. The learners were not familiar with the use of articles in English.

In punctuation, the largest number of errors observed is the use of semi colon in this category. In this sub- category, the number of the Iranian students' errors was 134 which came to $20 \%$ and their Indian peers' errors were 140 that constituted $19.5 \%$ of errors in punctuation. The minimum number of errors was quotation mark. In this sub- category, the Iranian students committed 50 errors which came to $7.5 \%$ and the Indian students' errors were 48 . They constituted $6.7 \%$ of errors. These errors were essentially the result of the learners did not know the basic rules of punctuation. They misused a series of the punctuation marks at their appropriate places.

In spelling, errors with spelling encompassed such sub-categories as "omission of letters," "addition of letters" and "replacement."The maximum error observed is the use of omission of letters. In this sub- category, the number of the Indian students' errors was 204 which came to $43.2 \%$ and their Iranian peers' errors were 247 which came to $42.7 \%$ for errors in spelling. The minimum number of errors was replacement. In this sub-category, the Iranian students committed 122 errors. They constituted 21.2 of errors for spelling. The Indian students' errors were 118 which came to $25 \%$ for errors in spelling. The students misused the correct spelling. They used additional vowel and consonants in wrong way or they omitted vowels and consonants in a wrong way. The errors may be understood to be result of confusion.

\section{THE HYPOTHESES OF THE STUDY}

The present hypotheses were made in order to identify the results of the various analyses regarding to the subjects errors in this research. The six hypotheses were formulated that are considered as follows:

H1. There is a significant difference in types of errors in writing between Iranian and Indian students. 
TABLE 3.

THE MEAN AND STANDARD DEVIATION OF WRITING ERRORS BETWEEN IRANIAN AND INDIAN STUDENTS

\begin{tabular}{|l|l|l|l|l|l|}
\hline Country & Mean & SD & T & dF & Sig. 2 tailed \\
\hline Iran & 26.25 & 6.40 & \multirow{2}{*}{1.327} & \multirow{2}{*}{.186} \\
\hline India & 27.42 & 6.10 & & \\
\hline
\end{tabular}

T-test was used to indicate whether there is a significant difference or not in types of errors in writing between Iranian and Indian students. Table 3 revealed that there is no significant difference in types of errors in writing between Iranian and Indian students. With respect to the mean scores the Indian students were $(\mathrm{M}=27.42-\mathrm{SD}=6.10)$ and the Iranian students $(M=26.25-\mathrm{SD}=6.40)$. We can arrive at this conclusion that there is no significant difference between these two groups of learners in writing. Meaning that although, the Indian students have committed more errors in writing when compared with their Iranian peers; this difference is so negligible that it is to be ignored.

H 2. There is a significant difference in types of errors in paragraph between Iranian and Indian students.

In paragraph type-I (topic sentence) there was no significant difference between the Iranian student and their counterparts in India. An investigation of table 4 supports this result.

TABLE 4.

THE MEAN AND STANDARD DEVIATION OF PARAGRAPH TYPE I (TOPIC SENTENCE) ERRORS BETWEEN IRANIAN AND INDIAN STUDENTS

\begin{tabular}{|l|l|l|l|l|l|}
\hline Country & Mean & SD & t & dF & Sig. 2 tailed \\
\hline Iran & .41 & .494 & .000 & 198 & \multirow{2}{*}{1.000} \\
\hline India & .41 & .494 & & \\
\hline
\end{tabular}

In paragraph type II (connectors) no significant difference was found between two groups. With reference to the mean scores it is clear that the Iranian and Indian students are similar in this regard.

TABLE 5.

THE MEAN AND STANDARD DEVIATION OF PARAGRAPH TYPE II (CONNECTORS) ERRORS BETWEEN IRANIAN AND INDIAN STUDENTS

\begin{tabular}{|l|l|l|l|l|l|}
\hline Country & Mean & SD & t & dF & Sig. 2 tailed \\
\hline Iran & .41 & .235 & 1.337 & \multirow{2}{*}{198} & .183 \\
\hline India & .37 & .208 & & \\
\hline
\end{tabular}

In paragraph type III (selected connectors) t-test revealed no significant difference between the students in Iran and India. The mean scores refer to this fact that these two groups are similar in term of using connectors in a proper place.

TABLE 6.

THE MEAN AND STANDARD DEVIATION OF PARAGRAPH TYPE III (SELECTED CONNECTORS) ERRORS BETWEEN IRANIAN AND INDIAN STUDENTS

\begin{tabular}{|l|l|l|l|l|l|}
\hline Country & Mean & SD & t & dF & Sig. 2 tailed \\
\hline Iran & .493 & .1917 & .409 & \multirow{2}{*}{198} & .683 \\
\hline India & .482 & .1921 & & \\
\hline
\end{tabular}

H 3.There is a significant difference in types of errors in punctuation between Iranian and Indian students.

In punctuation, Iranian students were not significantly different from Indian students, although Indian mean score was slightly higher than Iranian.

TABLE 7.

THE MEAN AND STANDARD DEVIATION OF PUNCTUATION ERRORS BETWEEN IRANIAN AND INDIAN STUDENTS

\begin{tabular}{|l|l|l|l|l|l|}
\hline Country & Mean & SD & t & dF & Sig. 2 tailed \\
\hline Iran & 6.54 & 1.720 & \multirow{2}{*}{1.341} & \multirow{2}{*}{.198} & .182 \\
\hline India & 6.89 & 1.964 & & \\
\hline
\end{tabular}

H 4. There is a significant difference in types of errors in articles between Iranian and Indian students.

In article category, a high significant difference was found between the mean scores. An investigation of mean scores clears that Indian students have committed more errors than Iranian students.

TABLE 8.

THE MEAN AND STANDARD DEVIATION OF ARTICLE ERRORS BETWEEN IRANIAN AND INDIAN STUDENTS

\begin{tabular}{|l|l|l|l|l|l|}
\hline Country & Mean & SD & t & dF & Sig. 2 tailed \\
\hline Iran & 6.26 & 2.325 & 4.303 & \multirow{2}{*}{198} & .000 \\
\hline India & 7.58 & 2.00 & & \\
\hline
\end{tabular}

H 5.There is a significant difference in types of errors in spelling between Iranian and Indian students.

In spelling category, t-test revealed a high significant difference between the students in two countries. An examination of table supports this result. Indian students in spelling category have committed fewer errors than Iranian. 
TABLE 9.

THE MEAN AND STANDARD DEVIATION OF SPELLING ERRORS BETWEEN IRANIAN AND INDIAN STUDENTS

\begin{tabular}{|l|l|l|l|l|l|}
\hline Country & Mean & SD & t & dF & Sig. 2 tailed \\
\hline Iran & 5.87 & 2.092 & 3.327 & \multirow{2}{*}{198} & .001 \\
\hline India & 4.83 & 2.323 & & \\
\hline
\end{tabular}

H 6.There is a significant difference in types of errors in conjunction between Iranian and Indian students.

In conjunction category, there was no significant difference between the means scores. It can be concluded that both students in Iran and India are equal in committing errors in this part of writing.

TABLE 10.

THE MEAN AND STANDARD DEVIATION OF CONJUNCTION ERRORS BETWEEN IRANIAN AND INDIAN STUDENTS

\begin{tabular}{|l|l|l|l|l|l|}
\hline Country & Mean & SD & t & dF & Sig. 2 tailed \\
\hline Iran & 6.32 & 2.558 & \multirow{2}{*}{1.379} & 198 & .169 \\
\hline India & 6.81 & 2.465 & & \\
\hline
\end{tabular}

\section{CONCLUSION AND SUGGESTION}

The results of this study, which in many ways is similar to the findings of previous studies, show that the second and foreign language learners are not aware of rules of English writing. Corder (1971) argued that the learners fill in the gaps in their competence of the target language with an interim language structure, an idiosyncratic dialect. Dulay and Burt (1974) indicated that "Researchers in various parts of the world have now become fully aware of the significance of the learners' errors, it is thought, are not only inevitable but also necessary" (cited in Pathak 1988). It was found that in general there exist systematic errors in learners' target language and teaching English and learning strategies could be responsible for the increase or decrease in the number of the written errors in the students' data in the two countries. Therefore, it seems that there are several other sources which could be held responsible for the occurrence of the errors in this research. The sources of the errors could be interference of the mother tongue of the students, complexity of the English language, students' incomplete knowledge or lack of knowledge of English writing.

However, the findings of this study revealed that the occurrence of all errors types found here any proportionally related to the knowledge of the subjects on the basis of English writing. Based on the above claims, the researcher believes that errors are an integral part of learning second/foreign language or is a natural part of the learner's gradual movement toward the development of communicative competence, and he/she should be allowed to make certain types of errors which do not greatly affect communication. According to Burt (1975) the distinction between "global" errors which causes a native speaker not to understand the message and "local" error that makes a sentence appear awkward but, nevertheless, a native speaker can understand the meaning of the sentence, suggests that the teacher should concentrate mainly on "global" errors which interfere with meanings. On the basis of Burt's suggestions, it would appear that "errors" which block communication should be corrected more promptly than those which do not greatly affect the transmission of the L2 speaker's message, it is important for the teachers to be aware of the basic position that errors, as a natural and indispensable part of the learning process, should neither be tolerated nor corrected excessively. Therefore, the main objective of L2 teaching is to develop the ability in the learner to communicate in the target language. The type of errors in this study revealed that the students did not have the ability in supplying the correct rules of English writing. They need more practice in the areas. Sufficient exercises should be built in order to increase their knowledge of English writing rules and reduce their errors. On the basis of insights gained into the nature of errors in second/foreign language learning, remedial measures should be recommended that enable the teacher to teach at the point of error, that is, teach those items which the students have most difficulty. The teacher should arrange the remedial materials on the basis of the degree of frequency recurrence.

\section{REFERENCES}

[1] Belhaj, A.M. (1997) Contrastive Textual Analysis: An Arabic -English, English-Arabic Translation Corpus. Occasional Papers, Vol, 24-25, 103-150.

[2] Bhatia, A. (1975). Error analysis and its implication for teaching. Indian Journal of Applied Linguistics, 12, 65-89.

[3] Burt, M.K. (1975). Error analysis in the adult EFL classroom. TESOL Quarterly, 9, 53-63.

[4] Corder,S.P. (1971). Idiosyncratic Dialects and Error Analysis. IRAL, 9, 147-160.

[5] Corder, S.P. (1973). Introducing Applied Linguistics. Harmonds Worth: Penguin.

[6] Corder, S.P. (1974). Error Analysis. IN Allen, J.L.P. and Corder, S.P. (1974). Techniques in Applied Linguistics. Oxford: Oxford University Press.

[7] Crystal, D. (1997). English as a global language. Cambridge: Cambridge University Press.

[8] Dulay, H.C. and Burt, M.K. (1974). "you cannot learn without Gooffing": An analysis of children's L2 errors. In Richards, J.C.(ed) (1974). Error Analysis: Perspectives on second language acquisition. London: Longman.

[9] Hendrikson, J. (1981). Error Analysis and Error Correction in Language Teaching. Singapore: SEA MEO Regional Language Center. 
[10] Kharma, N. (1981). Analysis of the errors committed by Arab University students in the use of the English definite and indefinite articles. IRAL, XIX, 333-345.

[11] Khansir, A. A. ( 2008 ). Syntactic Errors in English Committed by Indian Undergraduate Students. Language in India. Vol. $8,1-11$.

[12] Pathak, R.S. (1988). Error analysis of an Indian corpus. Indian Journal of Applied Linguistics, 14, 59-72.

[13] Radwan, M.A. (1988). A Linguistic Analysis of the Grammatical and Lexical Errors in the Nominal Group found in the Written English of Syrian University Students. Unpublished Ph.D. Dissertation, University of Nottingham. U.K.

[14] Ratna Shielamani, K. (1998). Errors in the usage of conjunctions by advanced learners. Indian Journal of Applied Linguistics, $24,71-81$

[15] Schachter, J. (1974). An error in error analysis. Language learning, 24, 205-214.

[16] Stig, J. (1975). "Problems in Studying the Communicative Effect of Learners' Errors," Colloque: Theoretical Models in Applied Linguistics IV. Universite de Neuchatel.

[17] Victor, W. (1973). Analysis of errors in composition writing. Journal of ELT, XXVII, 177-186

Ali Akbar Khansir is an Assistant professor in English Language Teaching at the Bushehr University of Medical Sciences and Health Services in Iran. He has completed M.A. in English Language Teaching at the Aligarh Muslim University in 2003 and PhD in English Language Teaching at the Mysore University in 2010 in India. He has published some articles in the field of Applied Linguistics and English Language Teaching in Academic Journals of English Language Teaching and Linguistics and published two books: English Error Analysis in 2010 and English Spelling and Sound in 2012 in Germany. 